\title{
Looking to the future: a new decade of pulmonary arterial hypertension therapy
}

\author{
V.V. McLaughlin
}

ABSTRACT: Pulmonary arterial hypertension (PAH) is a severe and debilitating disease characterised by vascular proliferation and remodelling of the small pulmonary arteries, leading to a progressive increase in pulmonary vascular resistance, increased afterload on the right ventricle and, ultimately, right heart failure. Although there is no "cure" for PAH, the availability of targeted therapies over the past decade has led to major advances in the management of PAH, reflected in improvements in survival in the modern treatment era. However, despite this, disease progression is inevitable in the majority of patients with PAH and overall the long-term prognosis, although improved, remains poor. There is a clear and urgent need for new therapeutic options, either through the development of improved drugs that act on targets established by existing PAH-specific therapies, or of agents targeting novel pathogenic pathways not addressed by currently available therapies. A number of such new agents that have shown promise in experimental models and preliminary human studies are discussed in this article.

KEYWORDS: Endothelin receptor antagonist, nitric oxide, prostacyclin, pulmonary arterial hypertension, serotonin receptor antagonist, tyrosine kinase inhibitor

$\mathbf{T}$ he treatment of pulmonary arterial hypertension (PAH) has evolved considerably over the past decade as a deeper understanding of the underlying pathogenesis of the disease and the mechanisms involved has led to the development of targeted therapeutic options. However, despite advances in treatment and improvements in outcome associated with the use of these targeted therapies, long-term prognosis remains poor. Recent data from the French Network on Pulmonary Hypertension registry showed that the survival rates for $\mathrm{PAH}$ patients managed in the modern treatment era were 83\% (95\% CI 72-95\%), $67 \%$ (95\% CI 57-79\%) and 58\% (95\% CI 49-69\%) at 1, 2 and 3 yrs, respectively [1]. Although this undoubtedly represents a marked improvement on the median survival of 2.8 yrs reported in the National Institutes of Health registry data from the 1980s [2], there is clearly still room for improvement.

Although associated with a range of underlying aetiologies, all forms of PAH share a common pulmonary arteriopathy characterised by vasoconstriction, remodelling of the pulmonary vessel wall and thrombosis in situ [3]. Originally considered to be a disorder of vasoconstriction and vasodilatation, it has become clear that the predominant characteristic of PAH is abnormal cellular proliferation leading to progressive obliteration of the pulmonary vasculature. There has, therefore, been an increasing interest over the past decade not only in agents which act as effective vasodilators, but also in those which have antiproliferative and anti-remodelling effects [4]. Current PAH-specific therapies target one of three major pathways involved in development and progression of PAH: 1) the endothelin pathway targeted by the endothelin receptor antagonists (ERAs); 2) the prostacyclin pathway, targeted by prostacyclin analogues; and 3) the nitric oxide (NO) pathway, targeted by the phosphodiesterase type-5 inhibitors (PDE-5i) [3]. While it is probable that further advances can be made using existing therapies (e.g. as part of combination regimens or in specific patient populations), there is also the need for the development of new treatment options, with improved efficacy, safety, tolerability and/or convenience profiles. There are two approaches that can be taken to develop new agents for continued improvements in the treatment of PAH: 1) new, more efficacious or more convenient drugs that act on established pathways already targeted by existing $\mathrm{PAH}-$ specific therapies; and 2) agents targeting novel pathogenic pathways that are emerging as a result of continued basic scientific research in the field.
CORRESPONDENCE

V.V. McLaughlin

University of Michigan Health System CVC Cardiovascular Medicine

1500 E Medical Center Dr

SPC 5853

Ann Arbor

Ml 48109-5853

USA

E-mail: vmclaugh@umich.edu

Received:

Aug 242011

Accepted after revision:

Sept 082011

PROVENANCE

Publication of this peer-reviewed article was supported by Actelion Pharmaceuticals Ltd, Switzerland (principal sponsor, European Respiratory Review issue 122). 
This article discusses the rationale and key data behind a number of these new agents that have shown promise in experimental models and preliminary human studies and which appear to have potential as future targeted strategies in PAH.

\section{NEW AGENTS TARGETING ESTABLISHED PATHWAYS IN PAH}

\section{Endothelin pathway}

Endothelin (ET)-1 has a well-established role in the pathogenesis of PAH. Treatment with ERAs has been shown to improve pulmonary haemodynamics, exercise capacity, functional status and clinical outcome in a number of randomised, placebo-controlled trials [5-12]. As well as its effects as a powerful vasodilator, ET-1 is implicated in vascular remodelling in PAH due to its ability to induce fibrosis [13], cell proliferation [14] and inflammation [15]. ET has a primarily paracrine effect, acting on local tissues to exert its effects. In fact, the majority $(80 \%)$ of the ET-1 produced by endothelial cells is secreted basolaterally and, therefore, into the tissue rather than apically into the bloodstream [16]. The effects of ET-1 are mediated by two cell surface ET receptor subtypes, both of which have been implicated in the pathological processes associated with PAH [17]: ETA receptors, found on pulmonary artery smooth muscle cells, pericytes and fibroblasts in the vessel walls; and ETB receptors present on endothelial cells, as well as pulmonary artery smooth muscle cells. Current ERAs show extremely limited tissue penetration due to their highly ionised state ( $\sim 99 \%$ for bosentan and $99.9 \%$ for ambrisentan [17]) which means only a small proportion of the drug can cross lipophilic cell membranes and, therefore, access ET receptors within the tissues. Improving tissue penetration and, thus, access to these receptors may increase the potency and efficiency of ERAs in PAH, not only with respect to an acute vasodilatory action, but also with regards to modulating vascular remodelling.

\section{Macitentan}

Macitentan is an oral dual (ETA and ETB) ERA designed to have improved tissue penetration due to an increased proportion of the non-ionised form of the molecule which is able to cross lipophilic cell membranes [17]. In the rat monocrotaline model of pulmonary hypertension, macitentan reduced mean pulmonary artery pressure $\left(\bar{P}_{\text {pa }}\right)$ and prevented right ventricular hypertrophy more effectively than bosentan, at a 10-fold lower dose, and resulted in significant improvements in survival [17]. Phase I and II clinical trials conducted to date have demonstrated that macitentan displays dose-dependent pharmacokinetics, and is well tolerated in healthy volunteers and hypertensive patients [18]. The phase III SERAPHIN trial, a multicentre, double-blind, placebo-controlled, event-driven study is currently underway, assessing the effects of macitentan on morbidity and mortality in patients with symptomatic PAH [19]. SERAPHIN is a long-term, event-driven trial and is the largest prospective study in PAH to date, including $\sim 180$ participating centres in over 40 countries with 742 patients enrolled. The primary end-point of the study is time to first morbidity or mortality. The events chosen as trial end-points reflect the recommendations from the proceedings of the 4th World Symposium [20], and are designed to be robust and clinically meaningful, with a broad application in practice (fig. 1). The long-term nature of this trial is particularly relevant given that patients with $\mathrm{PAH}$ are likely to require life-long therapy. Global enrolment for SERAPHIN was completed in December 2009 and results are expected mid-2012. The observation period is expected to last for at least $1 \mathrm{yr}$ for the

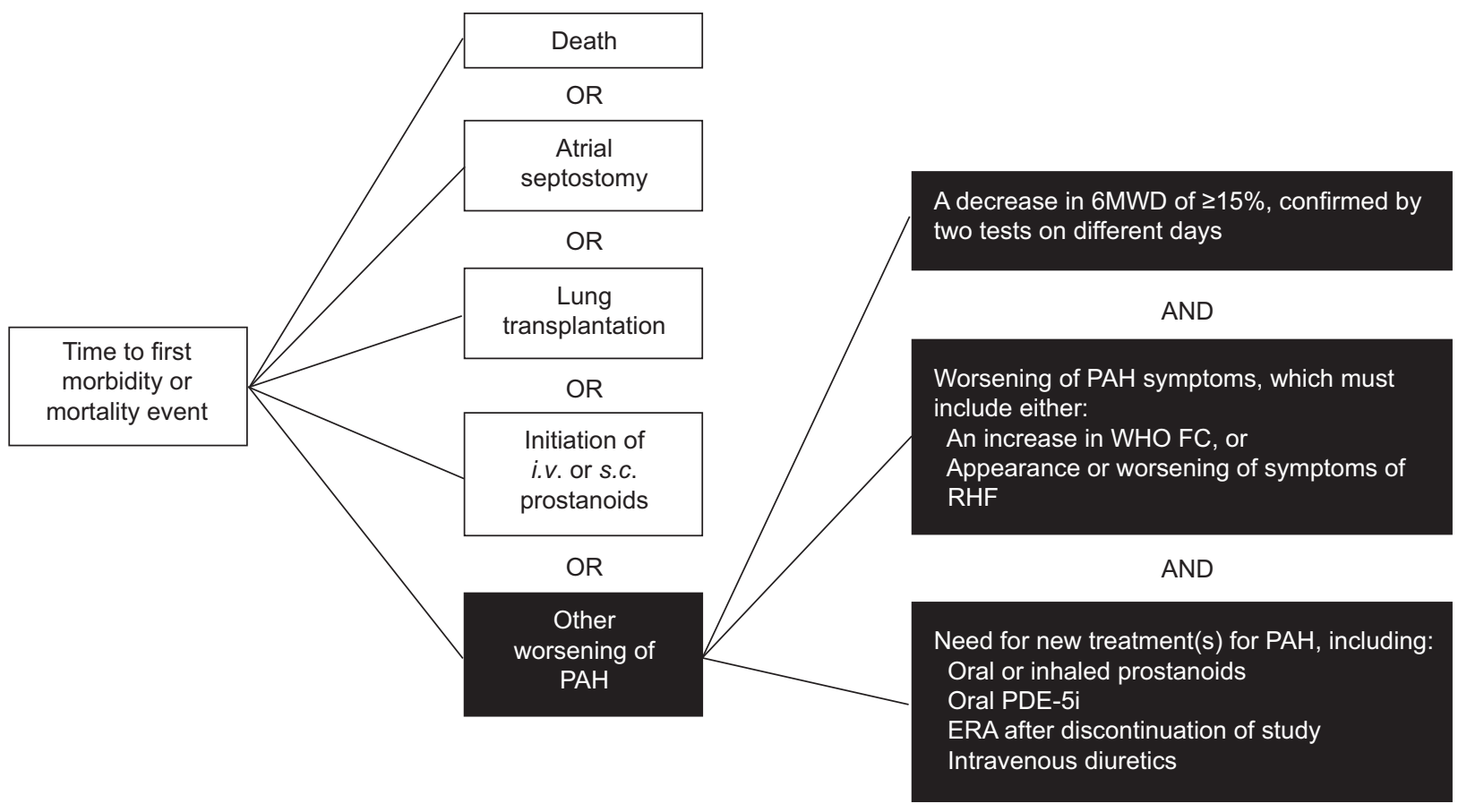

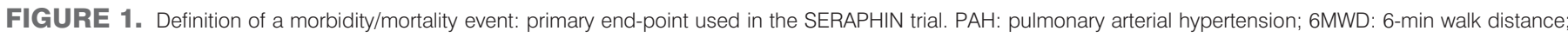
WHO FC: World Health Organization functional class; RHF: right heart failure; PDE-5i: phosphodiesterase-5 inhibitor; ERA: endothelin receptor antagonist. 
last enrolled patient and for up to 4.5 yrs for the first patient randomised. The availability of long-term morbidity and mortality data from a controlled clinical trial is not only beneficial for assessing the long-term outcomes of patients on the active drug, but will also provide valuable information on the natural history of PAH. While long-term survival data can be obtained from open-label extension studies of shorter trials, there is a bias towards over-estimation of survival as: only responders are entered into the extension phase; a lack of placebo arm means comparison has to be made with historical controls; and, also, the majority of patients enrolled are prevalent rather than incident patients. Therefore, survival data from longterm, placebo-controlled trials should provide a more accurate estimation of survival.

\section{Prostacyclin pathway}

Prostacyclin produced by the vascular endothelium is a powerful vasodilator that also has inhibitory effects on platelet aggregation, inflammation and vascular smooth muscle proliferation, all of which are implicated in the development of PAH. Intravenous prostacyclin (epoprostenol) was the first targeted therapy to be used to treat PAH. Treatment with epoprostenol results in symptomatic and haemodynamic improvements and has survival benefits [21-23]. However, its short serum half-life ( $\sim 6 \mathrm{~min})$ means epoprostenol needs to be administered by continuous infusion via an indwelling central venous catheter, which is associated with considerable inconvenience and a number of risks related to the delivery system, including infection and potentially life-threatening interruption of dosing due to pump failure. A number of prostacyclin analogues have been developed that attempt to overcome some of these limitations, including subcutaneous treprostinil [24, 25], inhaled iloprost [26-28] and inhaled treprostinil [29-31]. However, despite improving a number of clinical and haemodynamic parameters, neither analogue has demonstrated an impact on survival and each is associated with a range of disadvantages, including injection site reactions (treprostinil) and the need for frequent administration (iloprost). The first orally available prostacyclin, beraprost, improved exercise capacity and some clinical parameters in patients with $\mathrm{PAH}$ in the short term, but failed to improve functional class or haemodynamic parameters, or to provide long-term benefits [25, 32, 33].

\section{Selexipag}

Selexipag is an orally available prostacyclin IP receptor agonist which, as a diphenylpyrazine derivative, is chemically distinct from prostacyclin and prostacyclin analogues. Selexipag undergoes enzymatic hydrolysis [34] to yield a long-acting active metabolite (ACT-333679 or MRE-269; elimination half-life $\sim 8$ h) that is highly selective for the human prostacyclin IP receptor and, unlike prostacyclin analogues, does not activate other prostanoid receptors [35]. Selexipag exerts greater vasodilatory effects than either beraprost or iloprost which is probably related, at least in part, to the fact that unlike the latter agents, it does not have affinity for the EP3 receptor which mediates vasoconstriction [36]. In the rat monocrotaline model of pulmonary hypertension, treatment with selexipag ameliorated vascular endothelial dysfunction, pulmonary arterial wall hypertrophy and right ventricular hypertrophy, and significantly improved survival (45 day survival $73 \%$ versus $33 \%$ in rats administered vehicle alone; $\mathrm{p}=0.03$ ) [36]. A phase II study in patients with $\mathrm{PAH}$ found that selexipag was well tolerated at doses of $\leqslant 800 \mathrm{mg}$ twice daily, and treatment for 17 weeks resulted in a significant reduction in pulmonary vascular resistance (PVR; treatment effect $-33 \%$ versus placebo, $\mathrm{p}=0.0022$ ) (fig. 2) and a numerical, although nonsignificant, improvement in 6-min walk distance (6MWD; $+24.7 \mathrm{~m}$ change from baseline) [37]. Selexipag is currently being evaluated in the phase III GRIPHON trial, a double-blind, placebo-controlled, event-driven study with a primary end-point of time to first clinical event [38]. Preliminary data are expected in mid-2013.

\section{Oral treprostinil}

Oral treprostinil is a novel salt form of treprostinil (treprostinil diethanolamine), delivered via sustained release tablet to support twice-daily dosing. The phase II FREEDOM-C trial in patients with severe $\mathrm{PAH}$ failed to meet the primary end-point (significant improvement in 6MWD at week 16), possibly owing to issues regarding the initial titration of the drug, although significant improvements were seen in secondary efficacy measures [39]. Based on the dosing issues in this study, the phase III FREEDOM-M trial was modified, and was recently completed. A preliminary analysis suggests that the primary end-point was met with a significant median improvement of $25 \mathrm{~m}$ from baseline for patients who received oral treprostinil, compared with a decline of $5 \mathrm{~m}$ in the placebo group [40]. Patients completing FREEDOM-M are eligible for inclusion in the open-label extension FREEDOM-EXT, assessing treatment up to $1 \mathrm{yr}$ [41]. The FREEDOM-C(2) trial studies oral treprostinil in PAH patients who are receiving an ERA and/or a PDE-5i. Data from a preliminary analysis of the results of the trial are expected to be announced in late 2011 [42].

\section{NO pathway}

There is mounting evidence concerning the role of the NO pathway in the development and progression of PAH [43]. NO acts as a vasodilator and patients with $\mathrm{PAH}$ have been shown to have reduced levels of $\mathrm{NO}$ synthase and endogenous $\mathrm{NO}$ [44]. Although inhaled NO is widely used as a short-term vasodilator to identify patients with $\mathrm{PAH}$ who may respond to

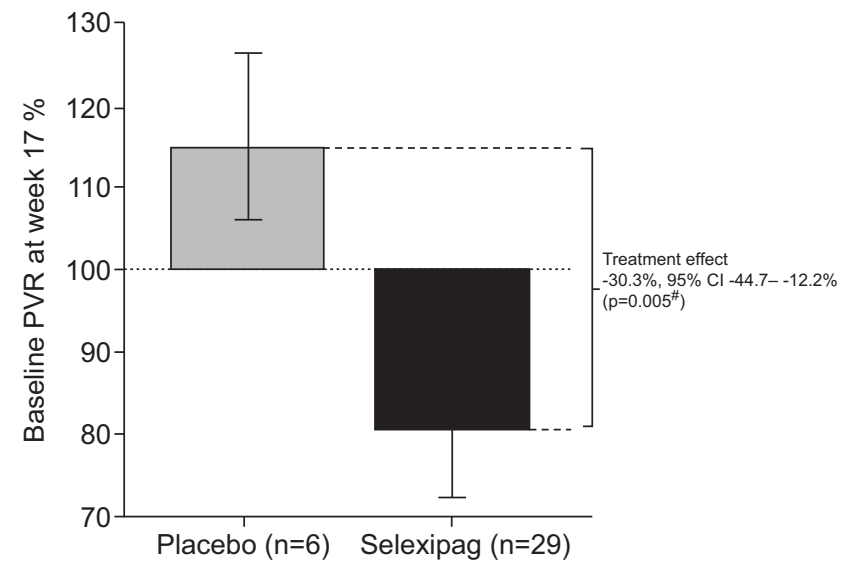

FIGURE 2. Change in pulmonary vascular resistance (PVR) from baseline to week 17 in a randomised, placebo-controlled phase II trial of selexipag in patients with pulmonary arterial hypertension. Data are presented as geometric means with 95\% confidence intervals. ${ }^{*}$ : Wilcoxon rank sum test. Reproduced from [37] with permission from the publisher. 
calcium channel blockers, its use as a therapeutic agent is restricted by technical problems during administration, and the potential for life-threatening rebound pulmonary hypertension should inhalation be interrupted or discontinued [45]. An alternative method of targeting the NO pathway is via the use of PDE-5i, which enhances the vasodilatory effects of endogenous NO by preventing the degradation of cyclic guanosine monophosphate (cGMP), promoting relaxation of vascular smooth muscle and increasing pulmonary blood flow. PDE-5i has shown short- and long-term benefit in PAH [4648], but treatment effects using PDE-5i alone are often unsatisfactory and, at present, no survival benefit of treatment has been shown.

\section{Riociguat}

Soluble guanylate cyclase (sGC) is a key signal-transduction enzyme activated by endothelial cell-derived NO [49]. sGC converts guanosine 5'-triphosphate to cGMP, leading to vasodilation and inhibition of platelet aggregation and vascular smooth cell proliferation [50]. Patients with pulmonary hypertension have been shown to express decreased levels of endothelial NO synthase, which is thought to contribute to pulmonary vasoconstriction and to the excessive growth of the tunica media associated with this disease [44]. Riociguat is a first-in-class, oral sGC stimulator that acts independently of NO and enhances the sensitivity of sGC to low levels of NO [49-52], which should, theoretically, result in a more potent therapeutic effect than PDE-5i which is dependent on baseline NO expression. In animal models of $\mathrm{PAH}$, riociguat improved pulmonary haemodynamics, and prevented and partially reversed remodelling of the small pulmonary arteries and right ventricle hypertrophy $[53,54]$. Riociguat significantly reduced $\bar{P}_{\text {pa, }}$ PVR and systemic vascular resistance and increased cardiac index $(\mathrm{p}<0.02$ compared with baseline for all measurements) in a proof of concept study [55]. In a phase II study in patients with moderate-to-severe (functional class II/III) PAH or chronic thromboembolic pulmonary hypertension (CTEPH), treatment with riociguat for 12 weeks was generally well tolerated and resulted in a significant reduction in PVR $\left(-215 \mathrm{dyn} \cdot \mathrm{s} \cdot \mathrm{cm}^{-5}\right.$ from baseline; $\mathrm{p}<0.0001)$ and an increase in 6MWD $(+55 \mathrm{~m}$ and $+57 \mathrm{~m}$ from baseline in patients with $\mathrm{CTEPH}$ and $\mathrm{PAH}$, respectively; $\mathrm{p}<0.0001$ for both) [51]. Riociguat is currently under investigation in two large placebo-controlled, phase III trials in patients with PAH [56] and CTEPH [57]. The primary end-points are change in 6MWD at week 12 and 16 of treatment, respectively, and the expected end dates are early and late 2012, respectively.

\section{AGENTS TARGETING NEW PATHWAYS IN PAH Tyrosine kinase inhibitors}

Abnormal pulmonary arterial vasoconstriction and structural remodelling of the pulmonary vessels are key aspects of the pathological processes contributing to the development of PAH. While pulmonary vasodilatation is a major effect of many current PAH-specific therapies, the vascular remodelling process itself is less targeted. Remodelling of the pulmonary arteries in PAH has been said to display many of the features considered to be hallmarks of cancer, such as enhanced cellular proliferation and suppressed apoptosis, changes in cellular metabolism and inflammation [58,59]. A variety of growth factors have been implicated in the abnormal cellular responses associated with pulmonary remodelling, including plateletderived growth factor (PDGF), basic fibroblast growth factor, epidermal growth factor and vascular endothelial growth factor, most of which act through the transmembrane receptor tyrosine kinases to activate major signalling transduction pathways [60]. A number of small molecule tyrosine kinase inhibitors have been developed for the treatment of cancer [61], and some of these have also been investigated in PAH [62]. However, safety concerns have arisen with these drugs in other conditions and, therefore, the issue of risk/benefit needs careful consideration in $\mathrm{PAH}$, especially with regards to cardiotoxicity [63].

\section{Imatinib}

PDGF has been implicated in the abnormal proliferation and migration of pulmonary vascular smooth muscle cells in $\mathrm{PAH}$ [64], and lung tissue from patients with $\mathrm{PAH}$ has been shown to have increased expression of PDGF receptors [53]. Imatinib is an orally administered PDGF inhibitor currently licensed for the treatment of chronic myelogenous leukaemia (CML) and certain gastrointestinal tumours. Inhibition of PDGF with imatinib was shown to reverse advanced pulmonary vascular disease in rat models of PAH [53]. In vitro, imatinib had anti-proliferative and pro-apoptotic effects on pulmonary artery smooth muscle cells from patients with PAH [65]. Clinically, treatment with imatinib has been shown to suppress upregulation of PDGF and improve haemodynamic parameters in some patients with $\mathrm{PAH}$ in case reports and small studies; however, a range of severe side-effects in some patients have been reported including renal dysfunction and hepatotoxicity [66-71]. A 24-week, phase II, proof of concept study in 59 patients with PAH (functional class II-IV) failed to achieve its primary end-point of a significant increase in 6MWD compared with placebo, although the imatinib group did show a mean improvement of $22 \mathrm{~m}$ compared with a decline of $1 \mathrm{~m}$ in the placebo group [68]. However, there were significant improvements in secondary end-points, including PVR (imatinib -300 versus placebo $-78 \mathrm{dyn} \cdot \mathrm{s} \cdot \mathrm{cm}^{-5} ; \mathrm{p}<0.01$ ) and cardiac output (imatinib +0.6 versus placebo $-0.1 \mathrm{~L} \cdot \mathrm{min}^{-1} ; \mathrm{p}=0.02$ ). Serious adverse events, including cardiac arrest, syncope and pre-syncope, liver dysfunction and worsening PAH, were seen in 39\% of patients treated with imatinib [68]. The phase III trial IMPRES [72] and its extension [73] are currently underway, with initial results expected in the near future.

\section{Nilotinib}

Nilotinib is a second generation oral tyrosine kinase inhibitor that was specifically designed to overcome the problems of resistance to imatinib which can develop during therapy for CML. In this setting, nilotinib has a more favourable safety profile than imatinib [74], although it is associated with a risk of cardiac complications, including QT prolongation and sudden cardiac death. In the rat monocrotaline model of $\mathrm{PAH}$, nilotinib was more effective than imatinib in reducing right ventricular pressure and Fulton index (a measure of right ventricular hypertrophy), and in improving pulmonary vasculature [75]. A 24-week, placebo-controlled, phase II study is currently underway to establish the efficacy, safety, tolerability and pharmacokinetics of nilotinib in patients with $\mathrm{PAH}$ who have an inadequate response to previous $\mathrm{PAH}$-specific therapy [76]. The primary end-point of the trial is change in PVR, and the trial is expected to complete in late 2011. 


\section{Serotonin receptor antagonists}

The involvement of the serotonin (5-HT) system in PAH was first suspected when it was recognised that the use of serotoninergic appetite suppressant drugs (aminorex and dexfenfluramine) markedly increased the risk of developing PAH [77]. Serotonin is thought to mediate $\mathrm{PAH}$ by promoting both vasoconstriction and remodelling of the pulmonary vasculature, inducing proliferation of pulmonary arterial fibroblasts and pulmonary arterial smooth muscle cells [78]. Both plasma serotonin levels and expression of the serotonin transporter have been reported to be increased in PAH $[79,80]$. Experimentally, exogenous serotonin can potentiate the development of hypoxia-induced $\mathrm{PAH}$ in rats [81], and inhibition of serotonin receptors or serotonin transporter can inhibit the development of PAH in animal models $[82,83]$. Clinically, selective serotonin reuptake inhibitors use has been shown to be associated with reduced mortality in patients with $\mathrm{PAH}$, although evidence in favour of their use is not strong $[84,85]$.

\section{Terguride}

Terguride modulates a range of neurotransmitter receptors including dopamine, $\alpha_{2}$-adrenergic receptors and serotonin. It is a strong anti-serotoninergic drug, acting as an antagonist of the 5-HT2 receptors which have been implicated in pathogenesis of PAH $[86,87]$. In vitro, proliferation and migration of cultured primary human pulmonary arterial smooth muscle cells are dose-dependently blocked by terguride [88]. Terguride inhibited the proliferation of pulmonary artery smooth muscle cells and abolished 5-HT-induced pulmonary vasoconstriction in monocrotaline-induced pulmonary hypertension in rats, and chronic administration resulted in a dose-dependent prevention of the development and progression of pulmonary hypertension in this model [88]. Phase II trials of terguride are underway in some EU countries (Austria, Switzerland, the Netherlands, Germany and Poland) in patients with PAH on stable treatment with best supportive care; the primary end-point is PVR following 12 weeks of treatment [89].

\section{Other therapies in early stage development}

Sorafenib is an oral multi-kinase inhibitor currently indicated for the treatment of advanced hepatocellular carcinoma and metastatic renal cancer. Sorafenib acts on a number of cellular targets including Raf- 1 kinase, a regulator of endothelial apoptosis, and angiogenic growth factor receptors such as vascular endothelial growth factor [90]. Studies in animal models of PAH showed that treatment with sorafenib resulted in improvements in haemodynamic parameters and attenuation of pulmonary hypertension [91], and prevention of pulmonary remodelling and improvement in cardiac and pulmonary function [60]. In a preliminary dosing study, 12 patients with advanced but stable PAH on parenteral prostanoids (with or without oral sildenafil) were initiated on $200 \mathrm{mg}$ sorafenib daily (the lowest active dosage administered to cancer patients) with dose escalations to a final dosage of $400 \mathrm{mg}$ twice daily [92]. Sorafenib was well tolerated at $200 \mathrm{mg}$ twice daily, and is currently under investigation in a phase I safety and tolerability study in patients with $\mathrm{PAH}$ already on existing therapy with a prostacyclin with or without sildenafil [93].

Sapropterin (6r-BH4) is the optically active form of tetrahydrobiopterin (BH4), an oral co-factor for NO synthesis. Animal studies have shown that a defect in endothelial NO synthesis function can be an initiating event leading to both pulmonary hypertension and pulmonary vascular remodelling, and that $\mathrm{BH} 4$ plays a pivotal role in endothelial NO synthesis function [94]. Clinically, treatment with sapropterin for 8 weeks in combination with sildenafil and/or an ERA resulted in improvements in 6MWD and was well tolerated [95]. A current phase I study of sapropterin in addition to current $\mathrm{PAH}$ therapy is underway [96].

Dicholoracetate has been shown to prevent and reverse monocrotaline-induced $\mathrm{PAH}$ in rats $[97,98]$ and partially regresses established pulmonary hypertension in mice [99]. A phase I trial of dichloroacetate added to current PAH therapy is currently underway in patients with PAH in functional class III-IV stable on their prescribed medical treatment (ERA and/ or PDE-5i) [100].

\section{CONCLUSIONS}

In depth understanding of the mechanisms of PAH pathogenesis has allowed for the development of drugs that target specific pathways. However, although these PAH-specific therapies have brought undoubted benefits, there is still considerable room for improvement, particularly in terms of long-term prognosis. As well as the development of new strategies using our existing armamentarium of targeted therapies, a number of new drugs are on the horizon that may bring further improvements in the management of PAH. In addition to therapies which target the endothelial control of pulmonary vascular tone and structure, new approaches, such as the use of antiproliferative agents that aim to actively limit pulmonary vascular remodelling, are being investigated and, as further insights into the pathogenesis of $\mathrm{PAH}$ are gained, it is likely that additional targets and strategies will be identified. Furthermore, the use of long-term, eventdriven trials for agents such as macitentan and selexipag will provide robust, clinically relevant data on which to base future treatment decisions. While much has been achieved in the field of $\mathrm{PAH}$ over the past decade, much remains to be done. It is anticipated that over the next decade, data from these on-going trials will drive major improvements in management options and, subsequently, in outcome for patients with this devastating disease.

\section{STATEMENT OF INTEREST}

V.V. McLaughlin has received speaking and/or consulting fees from Actelion, Bayer, Gilead, and United Therapeutics. The University of Michigan (Ann Arbor, MI, USA) has received research funding for multicentre trials from Actelion, Novartis, Pfizer and United Therapeutics.

\section{REFERENCES}

1 Humbert M, Sitbon O, Chaouat A, et al. Survival in patients with idiopathic, familial, and anorexigen-associated pulmonary arterial hypertension in the modern management era. Circulation 2010; 122: 156-163.

2 D'Alonzo GE, Barst RJ, Ayres SM, et al. Survival in patients with primary pulmonary hypertension. Results from a national prospective registry. Ann Intern Med 1991; 115: 343-349.

3 Humbert M, Sitbon O, Simonneau, G. Treatment of pulmonary arterial hypertension. N Engl J Med 2004; 351: 1425-1436. 
4 Rubin LJ. Therapy of pulmonary hypertension: the evolution from vasodilators to antiproliferative agents. Am J Respir Crit Care Med 2002; 166: 1308-1309.

5 Channick R, Badesch DB, Tapson VF, et al. Effects of the dual endothelin receptor antagonist bosentan in patients with pulmonary hypertension: a placebo-controlled study. J Heart Lung Transplant 2001; 20: 262-263.

6 Sitbon O, Badesch DB, Channick RN, et al. Effects of the dual endothelin receptor antagonist bosentan in patients with pulmonary arterial hypertension: a 1-year follow-up study. Chest 2003; 124: 247-254.

7 Sitbon O, McLaughlin VV, Badesch DB, et al. Survival in patients with class III idiopathic pulmonary arterial hypertension treated with first line oral bosentan compared with an historical cohort of patients started on intravenous epoprostenol. Thorax 2005; 60: 1025-1030.

8 Rubin LJ, Badesch DB, Barst RJ, et al. Bosentan therapy for pulmonary arterial hypertension. N Engl J Med 2002; 346: 896903.

9 McLaughlin VV, Sitbon O, Badesch DB, et al. Survival with firstline bosentan in patients with primary pulmonary hypertension. Eur Respir J 2005; 25: 244-249.

10 Galiè N, Olschewski H, Oudiz RJ, et al. Ambrisentan for the treatment of pulmonary arterial hypertension: results of the ambrisentan in pulmonary arterial hypertension, randomized, double-blind, placebo-controlled, multicenter, efficacy (ARIES) study 1 and 2. Circulation 2008; 117: 3010-3019.

11 McGoon MD, Frost AE, Oudiz RJ, et al. Ambrisentan therapy in patients with pulmonary arterial hypertension who discontinued bosentan or sitaxsentan due to liver function test abnormalities. Chest 2009; 135: 122-129.

12 Oudiz RJ, Galiè N, Olschewski H, et al. Long-term ambrisentan therapy for the treatment of pulmonary arterial hypertension. J Am Coll Cardiol 2009; 54: 1971-1981.

13 Shi-Wen X, Denton CP, Dashwood MR, et al. Fibroblast matrix gene expression and connective tissue remodeling: role of endothelin-1. J Invest Dermatol 2001; 116: 417-425.

14 Yang Z, Krasnici N, Lüscher TF. Endothelin-1 potentiates human smooth muscle cell growth to PDGF: effects of ETA and ETB receptor blockade. Circulation 1999; 100: 5-8.

15 Hocher B, Schwarz A, Fagan KA, et al. Pulmonary fibrosis and chronic lung inflammation in ET-1 transgenic mice. Am J Respir Cell Mol Biol 2000; 23: 19-26.

16 Wagner OF, Christ G, Wojta J, et al. Polar secretion of endothelin-1 by cultured endothelial cells. J Biol Chem 1992; 267: 16066-16068.

17 Iglarz M, Binkert C, Morrison K, et al. Pharmacology of macitentan, an orally active tissue-targeting dual endothelin receptor antagonist. J Pharmacol Exp Ther 2008; 327: 736-745.

18 Raja SG. Macitentan: a tissue-targeting endothelin receptor antagonist for the potential oral treatment of pulmonary arterial hypertension and idiopathic pulmonary fibrosis. Curr Opin Investig Drugs 2010; 11: 1066-1073.

19 ClinicalTrials.gov. Study of ACT-064992 on morbidity and mortality in patients with symptomatic pulmonary arterial hypertension. NCT00660179. http:/ / clinicaltrials.gov/ct2/show/ NCT00660179 Date last updated: May 20, 2011. Date last accessed: August 9, 2011.

20 McLaughlin VV, Badesch DB, Delcroix M, et al. End points and clinical trial design in pulmonary arterial hypertension. J Am Coll Cardiol 2009; 54: Suppl. 1, S97-S107.

21 Rubin LJ, Mendoza J, Hood M, et al. Treatment of primary pulmonary hypertension with continuous intravenous prostacyclin (epoprostenol). Results of a randomized trial. Ann Intern Med 1990; 112: 485-491.

22 Barst RJ, Rubin LJ, McGoon MD, et al. Survival in primary pulmonary hypertension with long-term continuous intravenous prostacyclin. Ann Intern Med 1994; 121: 409-415.
23 McLaughlin VV, Shillington A, Rich S. Survival in primary pulmonary hypertension: the impact of epoprostenol therapy. Circulation 2002; 106: 1477-1482.

24 Simonneau G, Barst RJ, Galie N, et al. Continuous subcutaneous infusion of treprostinil, a prostacyclin analogue, in patients with pulmonary arterial hypertension: a double-blind, randomized, placebo-controlled trial. Am J Respir Crit Care Med 2002; 165: 800-804.

25 Barst RJ, Galie N, Naeije R, et al. Long-term outcome in pulmonary arterial hypertension patients treated with subcutaneous treprostinil. Eur Respir J 2006; 28: 1195-1203.

26 Olschewski H, Simonneau G, Galiè N, et al. Inhaled iloprost for severe pulmonary hypertension. N Engl J Med 2002; 347: 322-329.

27 Olschewski H, Hoeper MM, Behr J, et al. Long-term therapy with inhaled iloprost in patients with pulmonary hypertension. Respir Med 2010; 104: 731-740.

28 Hoeper MM, Gall H, Seyfarth HJ, et al. Long-term outcome with intravenous iloprost in pulmonary arterial hypertension. Eur Respir J 2009; 34: 132-137.

29 Channick RN, Olschewski H, Seeger W, et al. Safety and efficacy of inhaled treprostinil as add-on therapy to bosentan in pulmonary arterial hypertension. J Am Coll Cardiol 2006; 48: 1433-1437.

30 Voswinckel R, Enke B, Reichenberger F, et al. Favorable effects of inhaled treprostinil in severe pulmonary hypertension: results from randomized controlled pilot studies. J Am Coll Cardiol 2006; 48: 1672-1681.

31 McLaughlin VV, Benza RL, Rubin LJ, et al. Addition of inhaled treprostinil to oral therapy for pulmonary arterial hypertension: a randomized controlled clinical trial. J Am Coll Cardiol 2010; 55: 1915-1922.

32 Galiè N, Humbert M, Vachiéry JL, et al. Effects of beraprost sodium, an oral prostacyclin analogue, in patients with pulmonary arterial hypertension: a randomized, double-blind, placebo-controlled trial. J Am Coll Cardiol 2002; 39: 1496-1502.

33 Barst RJ, McGoon M, McLaughlin V, et al. Beraprost therapy for pulmonary arterial hypertension. J Am Coll Cardiol 2003; 41: 2119-2125.

34 Mubarak KK. A review of prostaglandin analogs in the management of patients with pulmonary arterial hypertension. Respir Med 2010; 104: 9-21.

35 Kuwano K, Hashino A, Asaki T, et al. 2-[4-[(5,6-diphenylpyrazin2-yl)(isopropyl)amino]butoxy]- $\mathrm{N}$-(methylsulfonyl)acetamide (NS$304)$, an orally available and long-acting prostacyclin receptor agonist prodrug. J Pharmacol Exp Ther 2007; 322: 1181-1188.

36 Kuwano K, Hashino A, Noda K, et al. A long-acting and highly selective prostacyclin receptor agonist prodrug, 2-[4-[(5,6-diphenyl pyrazin-2-yl)(isopropyl)amino]butoxy]- $N$-(methylsulfonyl)acetamide (NS-304), ameliorates rat pulmonary hypertension with unique relaxant responses of its active form, [4-[(5,6-diphenylpyrazin-2yl)(isopropyl)amino]butoxy]acetic acid (MRE-269), on rat pulmonary artery. J Pharmacol Exp Ther 2008; 326: 691-699.

37 Simonneau G, Lang I, Torbicki A, et al. Efficacy, safety and tolerability of ACT-293987, a novel oral, non-prostanoid, prostaglandin I2 (IP) receptor agonist: results from a phase IIa study in pulmonary arterial hypertension (PAH). Am J Respir Crit Care Med 2010; 181: A2515.

38 ClinicalTrials.gov. ACT-293987 in pulmonary arterial hypertension. NCT01106014. http:/ / clinicaltrials.gov/ct2/show/NCT011 06014 Date last updated: July 27, 2011. Date last accessed: August 9 , 2011.

39 Tapson VF, Torres F, Kermeen F, et al. Results of the FREEDOM-C Study: a pivotal study of oral treprostinil used adjunctively with an ERA and/or PDE5-inhibitor for the treatment of PAH. Am J Respir Crit Care Med 2009; 179: A1040.

40 United Therapeutics. FREEDOM-M Trial of oral treprostinil in pulmonary arterial hypertension meets primary endpoint. 
http:/ /ir.unither.com/releasedetail.cfm?ReleaseID=582786 Date last updated: June 6, 2011. Date last accessed: August 9, 2011.

41 ClinicalTrials.gov. An open-label extension trial of UT-15C SR in subjects with pulmonary arterial hypertension (FREEDOM-EXT). NCT 01027949. http:/ / clinicaltrials.gov/ct2/show /NCT01027949 Date last updated October 8, 2010. Date last accessed: August 9, 2011.

42 ClinicalTrials.gov. A 16-week, international, multicenter, doubleblind, randomized, placebo-controlled study of the efficacy and safety of oral UT-15C sustained release tablets in subjects with pulmonary arterial hypertension (FREEDOM-C2). NCT00887978. http://clinicaltrials.gov/ct2/show/NCT00887978 Date last updated: May 5, 2011. Date last accessed: August 9, 2011.

43 Crosswhite P, Sun Z. Nitric oxide, oxidative stress and inflammation in pulmonary arterial hypertension. J Hypertens 2010; 28: 201-212.

44 Giaid A, Saleh D. Reduced expression of endothelial nitric oxide synthase in the lungs of patients with pulmonary hypertension. N Engl J Med 1995; 333: 214-221.

45 Sitbon O, Brenot F, Denjean A, et al. Inhaled nitric oxide as a screening vasodilator agent in primary pulmonary hypertension. A dose-response study and comparison with prostacyclin. Am J Respir Crit Care Med 1995; 151: 384-389.

46 Galiè N, Ghofrani HA, Torbicki A, et al. Sildenafil citrate therapy for pulmonary arterial hypertension. N Engl J Med 2005; 353: 2148-2157.

47 Rubin LJ, Badesch DB, Fleming TR, et al. Long-term treatment with sildenafil citrate in pulmonary arterial hypertension: SUPER-2. Chest 2011; [Epub ahead of print DOI: 10.1378/ chest.10-0969].

48 Galiè N, Brundage BH, Ghofrani HA, et al. Tadalafil therapy for pulmonary arterial hypertension. Circulation 2009; 119: 28942903.

49 Ghofrani HA, Voswinckel R, Gall H, et al. Riociguat for pulmonary hypertension. Future Cardiol 2010; 6: 155-166.

50 Evgenov OV, Kohane DS, Bloch KD, et al. Inhaled agonists of soluble guanylate cyclase induce selective pulmonary vasodilation. Am J Respir Crit Care Med 2007; 176: 1138-1145.

51 Ghofrani HA, Hoeper MM, Halank M, et al. Riociguat for chronic thromboembolic pulmonary hypertension and pulmonary arterial hypertension: a phase II study. Eur Respir J 2010; 36: 792-799.

52 Mittendorf J, Weigand S, Alonso-Alija C, et al. Discovery of riociguat (BAY 63-2521): a potent, oral stimulator of soluble guanylate cyclase for the treatment of pulmonary hypertension. ChemMedChem 2009; 4: 853-865.

53 Schermuly RT, Dony E, Ghofrani HA, et al. Reversal of experimental pulmonary hypertension by PDGF inhibition. J Clin Invest 2005; 115: 2811-2821.

54 Schermuly RT, Stasch JP, Pullamsetti SS, et al. Expression and function of soluble guanylate cyclase in pulmonary arterial hypertension. Eur Respir J 2008; 32: 881-891.

55 Grimminger F, Weimann G, Frey R, et al. First acute haemodynamic study of soluble guanylate cyclase stimulator riociguat in pulmonary hypertension. Eur Respir J 2009; 33: 785-792.

56 ClinicalTrials.gov. A study to evaluate efficacy and safety of oral BAY63-2521 in patients with pulmonary arterial hypertension (PAH) (PATENT-1). NCT00810693. http://clinicaltrials.gov/ ct2/show/NCT00810693 Date last updated: August 4, 2011. Date last accessed: August 9, 2011.

57 ClinicalTrials.gov. A study to evaluate efficacy and safety of oral BAY63-2521 in patients with CTEPH (CHEST-1). NCT00855465. http:/ / clinicaltrials.gov/ct2/show/NCT00855465 Date last updated: July 27, 2011. Date last accessed: August 9, 2011.

58 Paulin R, Courboulin A, Barrier M, et al. From oncoproteins/ tumor suppressors to microRNAs: the newest therapeutic targets for pulmonary arterial hypertension. J Mol Med (Berl) 2011; [Epub ahead of print DOI: 10.1007/s00109-011-0788-5].
59 Sakao S, Tatsumi K. Vascular remodeling in pulmonary arterial hypertension: multiple cancer-like pathways and possible treatment modalities. Int J Cardiol 2011; 147: 4-12.

60 Klein M, Schermuly RT, Ellinghaus P, et al. Combined tyrosine and serine/threonine kinase inhibition by sorafenib prevents progression of experimental pulmonary hypertension and myocardial remodeling. Circulation 2008; 118: 2081-2090.

61 Steeghs N, Nortier JW, Gelderblom H. Small molecule tyrosine kinase inhibitors in the treatment of solid tumors: an update of recent developments. Ann Surg Oncol 2007; 14: 942-953.

62 Grimminger F, Schermuly RT. PDGF receptor and its antagonists: role in treatment of PAH. Adv Exp Med Biol 2010; 661: 435-446.

63 Kerkela R, Grazette L, Yacobi R, et al. Cardiotoxicity of the cancer therapeutic agent imatinib mesylate. Nature Med 2006; 12: 908-916.

64 Barst RJ. PDGF signaling in pulmonary arterial hypertension. J Clin Invest 2005; 115: 2691-264.

65 Nakamura K, Akagi S, Ogawa A, et al. Pro-apoptotic effects of imatinib on PDGF-stimulated pulmonary artery smooth muscle cells from patients with idiopathic pulmonary arterial hypertension. Int J Cardiol 2011; [Epub ahead of print DOI: 10.1016/ j.ijcard.2011.02.024].

66 Hatano M, Yao A, Shiga T, et al. Imatinib mesylate has the potential to exert its efficacy by down-regulating the plasma concentration of platelet-derived growth factor in patients with pulmonary arterial hypertension. Int Heart J 2010; 51: 272-276.

67 Ghofrani HA, Seeger W, Grimminger F. Imatinib for the treatment of pulmonary arterial hypertension. N Engl J Med 2005; 353: 1412-1413.

68 Ghofrani HA, Morrell NW, Hoeper MM, et al. Imatinib in pulmonary arterial hypertension patients with inadequate response to established therapy. Am J Respir Crit Care Med 2010; 182: 1171-1177.

69 Souza R, Sitbon O, Parent F, et al. Long term imatinib treatment in pulmonary arterial hypertension. Thorax 2006; 61: 736.

70 ten Freyhaus H, Dumitrescu D, Bovenschulte H, et al. Significant improvement of right ventricular function by imatinib mesylate in scleroderma-associated pulmonary arterial hypertension. Clin Res Cardiol 2009; 98: 265-267.

71 García Hernández FJ, Castillo Palma MJ, González León R, et al. Experience with imatinib to treat pulmonary arterial hypertension. Arch Bronconeumol 2008; 44: 689-691.

72 ClinicalTrials.gov. Imatinib in pulmonary arterial hypertension (IMPRES). NCT00902174. http://clinicaltrials.gov/ct2/show/ NCT00902174 Date last updated: December 1, 2010. Date last accessed: August 9, 2011.

73 ClinicalTrials.gov. Extension to QTI571A2301 to evaluate the long-term safety, tolerability and efficacy of imatinib in severe pulmonary arterial hypertension (IMPRES Extn). NCT01117987. http://clinicaltrials.gov/ct2/show/NCT01117987 Date last updated: October 22, 2011. Date last accessed: August 9, 2011.

74 Kantarjian H, Giles F, Wunderle L, et al. Nilotinib in imatinibresistant CML and Philadelphia chromosome-positive ALL. N Engl J Med 2006; 354: 2542-2551.

75 Duggan N, Bonneau O, Hussey M, et al. Comparison of effects of imatinib and nilotinib in a rodent model of pulmonary arterial hypertension. Am J Respir Crit Care Med 2010; 181: A6304.

76 ClinicalTrials.gov. Efficacy, safety, tolerability and pharmacokinetics (PK) of nilotinib (AMN107) in pulmonary arterial hypertension (PAH). NCT01179737. http://clinicaltrials.gov/ ct2/show/NCT01179737 Date last updated: August 10, 2010. Date last accessed: August 9, 2011.

77 Abenhaim L, Moride Y, Brenot F, et al. Appetite-suppressant drugs and the risk of primary pulmonary hypertension. International Primary Pulmonary Hypertension Study Group. N Engl J Med 1996; 335: 609-616. 
78 Dempsie Y, MacLean MR. Pulmonary hypertension: therapeutic targets within the serotonin system. Br J Pharmacol 2008; 155: 455-462.

79 Hervé P, Launay J-M, Scrobohaci M-L, et al. Increased plasma serotonin in primary pulmonary hypertension. Am J Med 1995; 99: 249-254.

80 Eddahibi S, Humbert M, Fadel E, et al. Serotonin transporter overexpression is responsible for pulmonary artery smooth muscle hyperplasia in primary pulmonary hypertension. J Clin Invest 2001; 108: 1141-1150.

81 Eddahibi S, Raffestin B, Pham I, et al. Treatment with 5-HT potentiates development of pulmonary hypertension in chronically hypoxic rats. Am J Physiol Heart Circ Physiol 1997; 41: H1173-H1181.

82 Hironaka E, Hongo M, Sakai A, et al. Serotonin receptor antagonist inhibits monocrotaline-induced pulmonary hypertension and prolongs survival in rats. Cardiovasc Res 2003; 60: 692-699.

83 Guignabert C, Raffestin B, Benferhat R, et al. Serotonin transporter inhibition prevents and reverses monocrotaline-induced pulmonary hypertension in rats. Circulation 2005; 111: 2812-2819.

84 Kawut SM, Horn EM, Berekashvili KK, et al. Selective serotonin reuptake inhibitor use and outcomes in pulmonary arterial hypertension. Pulmon Pharmacol Therapeut 2006; 19: 370-374.

85 Shah SJ, Gomberg-Maitland M, Thenappan T, et al. Selective serotonin reuptake inhibitors and the incidence and outcome of pulmonary hypertension. Chest 2009; 136: 694-700.

86 Keegan A, Morecroft I, Smillie D, et al. Contribution of the 5$\mathrm{HT}(1 \mathrm{~B})$ receptor to hypoxia-induced pulmonary hypertension: converging evidence using 5-HT(1B)-receptor knockout mice and the 5-HT(1B/1D)-receptor antagonist GR127935. Circ Res 2001; 89: 1231-1239.

87 Launay JM, Hervé $P$, Peoc'h K, et al. Function of the serotonin 5hydroxytryptamine $2 \mathrm{~B}$ receptor in pulmonary hypertension. Nat Med 2002; 8: 1129-1135.

88 Dumitrascu R, Kulcke C, Königshoff M, et al. Terguride ameliorates monocrotaline induced pulmonary hypertension in rats. Eur Respir J 2011; 37: 1104-1118.

89 Ergonex. Ergonex Pharma initiates Phase II clinical trial of terguride in pulmonary arterial hypertension. www.ergonex. com/attachments/news/26/Media_Release_final_V2.pdf Date last updated: January 29, 2008. Date last accessed: August 9, 2011.
90 Wilhelm SM, Carter C, Tang L, et al. BAY 43-9006 exhibits broad spectrum oral antitumor activity and targets the RAF/MEK/ ERK pathway and receptor tyrosine kinases involved in tumor progression and angiogenesis. Cancer Res 2004; 64: 7099-7109.

91 Moreno-Vinasco L, Garcia JG. Receptor tyrosine kinase inhibitors in rodent pulmonary hypertension. Adv Exp Med Biol 2010; 661: 419-434.

92 Gomberg-Maitland M, Maitland ML, Barst RJ, et al. A dosing/ cross-development study of the multikinase inhibitor sorafenib in patients with pulmonary arterial hypertension. Clin Pharmacol Ther 2010; 87: 303-310.

93 ClinicalTrials.gov. Sorafenib study: dosing in patients with pulmonary arterial hypertension (PAH). NCT00452218. http:// clinicaltrials.gov/ct2/show/NCT00452218 Date last updated: August 2, 2011. Date last accessed: August 9, 2011.

94 Pritchard KA Jr, Shi Y, Konduri GG. Tetrahydrobiopterin in pulmonary hypertension: pulmonary hypertension in guanosine triphosphate-cyclohydrolase-deficient mice. Circulation 2005; 111: 2022-2024.

95 Robbins IM, Hemnes AR, Gibbs JS, et al. Safety of sapropterin dihydrochloride (6r-bh4) in patients with pulmonary hypertension. Exp Lung Res 2011; 37: 26-34.

96 ClinicalTrials.gov. 6R-BH4 pulmonary arterial hypertension study NCT00435331. http://clinicaltrials.gov/ct2/show/NCT00435331 Date last updated: April 17, 2011. Date last accessed: August 9, 2011.

97 McMurtry MS, Bonnet S, Wu X, et al. Dichloroacetate prevents and reverses pulmonary hypertension by inducing pulmonary artery smooth muscle cell apoptosis. Circ Res 2004; 95: 830-840.

98 Michelakis ED, McMurtry MS, Wu XC, et al. Dichloroacetate, a metabolic modulator, prevents and reverses chronic hypoxic pulmonary hypertension in rats: role of increased expression and activity of voltage-gated potassium channels. Circulation 2002 105: 244-250.

99 Guignabert C, Tu L, Izikki M, et al. Dichloroacetate treatment partially regresses established pulmonary hypertension in mice with SM22alpha-targeted overexpression of the serotonin transporter. FASEB J 2009; 23: 4135-4147.

100 ClinicalTrials.gov. Dichloroacetate (DCA) for the treatment of pulmonary arterial hypertension. NCT01083524. http:/ / clinicaltrials.gov/ct2/show/NCT01083524 Date last updated: March 9, 2010. Date last accessed: August 9, 2011. 